ASPECTOS DINÂMICOS E QUALITATIVOS DA POLÍTICA PÚBLICA MUNICIPAL DE FOMENTO AO COOPERATIVISMO

\title{
DYNAMIC AND QUALITATIVE ASPECTS OF THE CYCLE OF MUNICIPAL PUBLIC POLICY TO PROMOTE COOPERATIVISM
}

Karita Carneiro Pereira Scotta ${ }^{1}$

\section{RESUMO}

Este artigo que tem como objetivo analisar a dinâmica institucional da política pública municipal de fomento ao cooperativismo, entre os anos de 2013 e 2017, no município de Gurupi-TO, especificamente avaliar qualitativamente a dinâmica institucional da política pública municipal para o cooperativismo com base na percepção dos gestores públicos, dirigentes e beneficiários em relação ao desempenho qualitativo da política pública municipal e identificar os desafios e propor diretrizes para a consolidação da gestão da política pública de fomento ao cooperativismo no município de Gurupi-TO. Trata-se de uma pesquisa de abordagem qualitativa, com coleta de dados via pesquisa bibliográfica e documental com realização de entrevistas semiestruturadas com ex-gestores e dirigente que participaram e participam da condução da referida política e com os beneficiários (pequenos produtores da agricultura familiar). Portanto, vislumbrou a convergência dos interesses da gestão pública com o cooperativismo local com destaque de elementos que podem contribuir para a consolidação da política pública de fomento ao cooperativismo no município proposto por meio da avaliação política considerando os aspectos da legitimidade do processo de elaboração das ações, a percepção dos beneficiários da política pública com a indicação dos benefícios e impactos na condução da política pública de fomento ao cooperativismo local.

Palavras-chave: Cooperativismo. Gestão de Políticas Públicas. Avaliação de Política Pública Municipal.

\section{ABSTRACT}

This article aims to analyze the institutional dynamics of the municipal public policy to promote cooperativism, between 2013 and 2017, in the municipality of Gurupi-TO, to qualitatively evaluate the dynamics of the institutional cycle of municipal public policy for cooperativism in Gurupi-To based on the perception of public managers, managers and beneficiaries in relation to the qualitative performance of the municipal public policy and to identify the challenges and propose guidelines for the consolidation of the management of the public policy to foment the cooperativism in the municipality of Gurupi-TO. This is a qualitative research, with data collection through bibliographical and documentary research and semi-structured interviews with ex-managers and managers who participated in and participated in the conduct of this policy and with the beneficiaries (small producers of family agriculture). Therefore, he envisaged the convergence of public management interests with local cooperativism, highlighting elements that may contribute to the consolidation of the public policy of fomenting cooperativism in Gurupi-TO by means of the political evaluation considering the aspects of the legitimacy of the process of elaboration of the actions, the perception of the beneficiaries of the public public policy with the indication of the benefits and impacts in the conduct of the public policy of foment to the cooperativism.

Keywords: Cooperativism. Public Policy Management. Analysis of Municipal Public Policy.
1 Mestra em Gestão de Políticas Públicas. Professora Adjunta da Universidade Estadual do Tocantins (UNITINS). Professora Assistente da Universidade de Gurupi (UNIRG).

e-mail:

karitacarneiropereira@gmail.com 


\section{INTRODUÇĀO}

O presente trabalho possui abrangência local, visto que a nuance de investigação visa abordar a dinâmica da política pública ${ }^{1}$ de fomento ao cooperativismo do município de Gurupi-TO. O município está localizado ao sul do Estado às margens da BR-153, sendo o terceiro maior em contingente populacional do Estado do Tocantins, com população estimada, em julho de 2017, de 85.523 habitantes (IBGE, 2010).

No Brasil, existem políticas públicas que nascem tal como a teoria prevê, ou seja, se iniciando por um amplo processo de diagnóstico da situação a ser tratada, passando por uma fase de planejamento, pelo estabelecimento de diretrizes, pela definição do modelo de implementação, pela realização de testes, pela implantação propriamente dita da política e, por fim, pela sua avaliação e monitoramento, entre outras fases (DIAS, 2012; FREY, 2000). Entretanto, o surgimento de políticas públicas, que não consideram várias dessas importantes etapas é algo que acontece com frequência.

O que se verifica, em síntese, é que os modelos descritores do ciclo de políticas públicas raramente refletem a real dinâmica de uma política pública (SECCHI, 2010). De um modo geral o processo de uma política pública é incerto, sendo pouco nítidas as fronteiras entre suas diversas fases, sendo que estas se apresentam sobrepostas, e algumas etapas se antecipam a outras.

Em muitos casos, as políticas públicas podem surgir para tratar dos problemas existentes identificados, sem considerar a fundo as causas desses problemas. Nem sempre o governo possui tempo hábil para efetuar um adequado processo de planejamento de suas políticas.

Assim, o estudo adequado sobre o processo de implantação de uma política não é suficientemente realizado, colocando em xeque a qualidade do gasto e investimento público em geral, que diz respeito ao contexto e a forma pela qual as políticas públicas são formuladas, implementadas e avaliadas.

Diante dessas observações, torna-se necessário explicitar que este estudo é voltado para a gestão de políticas públicas na construção/condução de políticas públicas para o fomento do cooperativismo.

Por esse motivo, se propõe a avaliar de forma qualitativa a dinâmica política pública municipal de fomento ao cooperativismo, no município de Gurupi-TO a fim de orientar as

\footnotetext{
${ }^{1}$ A correta compreensão do ciclo das políticas pode ser de grande valia para o gestor, favorecendo seu entendimento correto do processo das políticas públicas e auxiliando-o a refletir com clareza sobre como e mediante que instrumentos as políticas poderão ser aperfeiçoadas.
} 
ações de governança, com vistas a contribuir para a formação de um ambiente mais seguro e favorável para que a política pública de cooperativismo local e regional apresente resultados efetivamente transformadores, à altura das expectativas da sociedade e na concretização dos direitos sociais, previstos na Carta Magna Constituição Federal de 1988.

A pesquisa parte das seguintes problemáticas: De que maneira a dinâmica institucional da política pública municipal de cooperativismo contribui para a consolidação do cooperativismo no município de Gurupi-TO? Quais os desafios e possibilidades da gestão de políticas públicas e do cooperativismo no município de Gurupi-TO? Para tanto, buscará demonstrar a convergência dos interesses entre a gestão de políticas públicas e o cooperativismo para a efetiva consolidação da política municipal de fomento ao cooperativismo no município de Gurupi-TO.

As cooperativas vão além dos padrões de políticas de responsabilidade social adotadas pelas empresas mercantis, uma vez que "a participação democrática e a educação cooperativista pretendem construir novas relações entre as pessoas, o que também repercutiria na comunidade, contribuindo, assim, para o desenvolvimento e a promoção da cidadania" (MILAGRES; AMODEO e SOUZA, 2011, p.72).

Desta forma, tem-se como objetivos analisar a dinâmica institucional da política pública municipal de fomento ao cooperativismo, entre os anos de 2013 e 2017, no município de Gurupi-TO, especificamente avaliar qualitativamente a dinâmica do ciclo institucional da política pública municipal para o cooperativismo em Gurupi-To com base na percepção dos gestores públicos, dirigentes e beneficiários em relação ao desempenho qualitativo da política pública municipal e identificar os desafios e propor diretrizes para a consolidação da gestão da política pública de fomento ao cooperativismo no município de Gurupi-TO.

A pesquisa se justifica pela pouca densidade de trabalhos científicos sobre gestão de políticas públicas em âmbito municipal, especialmente em municípios do Estado do Tocantins, pretendendo contribuir no aspecto teórico para os atores políticos e sociais envolvidos com o cooperativismo e com a gestão de políticas públicas.

A parte metodológica traz uma abordagem qualitativa, com coleta de dados via pesquisa bibliográfica e de documental e realização de entrevistas semiestruturadas com ex-gestores e dirigente que participaram e participam da condução da referida política e com os beneficiários (pequenos produtores da agricultura familiar). Os dados coletados foram categorizados e submetidos à análise de conteúdo. 
O trabalho está estruturado em seções sendo a primeira essa introdução. A segunda seção versa sobre a definição conceitual de políticas públicas, abordando a importância dessa área de conhecimento suas delimitações conceituais e a avaliação das políticas públicas.

A terceira seção trata do cooperativismo, estabelecendo a evolução histórica e o atual estado dos princípios cooperativistas, o cooperativismo no Brasil, no Estado do Tocantins e no município de Gurupi-TO.

A quarta seção descreve a metodologia empregada na pesquisa e forma de coleta e análise dos dados. Na quinta seção traz a análise, discussão dos resultados e por fim são apresentadas as considerações finais do estudo.

\section{DEFINICGAO DE POLITICAS PUBLICAS}

O Brasil é um país historicamente marcado por sua diversidade natural e cultural. Da mesma forma, é notória a existência de desigualdades sociais e econômicas, como demonstram as estatísticas oficiais (PEREIRA, 2011).

Apesar de se tratar de fenômenos diversos, a pobreza, a desigualdade e a exclusão social estão intimamente inter-relacionadas, posto que a pobreza no Brasil não esteja determinada pela escassez de recursos e sim pela desigualdade na distribuição da renda e das oportunidades de inclusão econômica e social, conforme demonstra Barros (2004).

Neste sentido, importante frisar as definições e fundamentos das políticas públicas, bem como as formas de consecução de seus objetivos.

Conforme Secchi (2015), a política, a partir do termo americano policy, refere-se ao posicionamento e orientações para a decisão e ação, fato que the confere uma dimensão mais prática e, assim, facilita compreender sua função no contexto social.

O autor menciona, ainda, que nas decisões políticas instituídas no âmbito do Estado há participação de diversos atores, dentre os quais se destacam os partidos políticos, agentes governamentais e diversos outros atores sociais, como representantes de movimentos sociais, de organizações não governamentais (ONGs) e da iniciativa privada.

Pode-se compreender as políticas públicas tomando por base duas correntes de pensamento: a norte-americana, centrada na ação de analisar as políticas públicas dentro uma lógica utilitarista, do ponto de vista de custos e resultados. E existe a outra vertente, a europeia que analisa as políticas públicas como um processo político e coletivo. Assim há a necessidade de discurso entre a ação do governo e a teoria de estado, em especial 
DOI: $10.18605 / 2175-7275 /$ cereus.v11n4p99-122

Revista Cereus

2019, vol. 11, nำ 4 .
Scotta, K.C.P.

Aspectos dinâmicos e qualitativos da política pública municipal de fomento ao cooperativismo.

a que preza pelo coletivo, já que as políticas públicas têm como finalidade atender ao bem-estar da sociedade.

As políticas públicas são direcionadas a solucionar demandas da coletividade, podendo incidir na vida privada dos cidadãos, sendo possível que as entidades privadas participem de sua formulação ou compartilhem sua implementação, e a possibilidade de o fazerem está amparada em decisões públicas, ou seja, decisões tomadas por agentes governamentais, emanadas do poder imperativo do Estado. E, para efeito acadêmico, apresenta-se uma síntese teórico conceitual, na Tabela 1 adiante.

\section{TABELA 1. QUADRO TEÓRICO-CONCEITUAL DE 'POLÍTICAS PÚBLICAS'}

Autor "as políticas públicas eram, de fato, a concretização do governo em ação, quase um ato de

Laswell

(1950) governing, conjugado com o tempo verbal no gerúndio), seus estudos deveriam também assumir a intencionalidade de tais ações adotando uma perspectiva prescritiva, de forma que as decisões e análises sobre política pública convirja à responder às seguintes indagações: quem ganha o quê, por que e que diferença faz."
Dye (1972) descreve a política pública como "tudo o que um governo decide fazer ou deixar de fazer".
Jenkins "conjunto de decisões inter-relacionadas tomadas por um ator individual ou por um conjunto de (1978) atores, referentes à seleção de objetivos e de meios para atingi-los em uma situação em que atores possuem condições de alcançar tais objetivos".

Souza "Campo do conhecimento que busca, ao mesmo tempo, "colocar o governo em ação" e/ou (2006) analisar essa ação (variável independente) e, quando necessário propor mudanças no rumo ou curso dessas ações (variável dependente)".

"Não existe uma única, nem melhor, definição sobre o que seja política pública. Mead (1995) a define como um campo dentro do estudo da política que analisa o governo à luz de grandes questões públicas e Lynn (1980), como um conjunto de ações do governo que irão produzir efeitos específicos. Peters (1986) segue o mesmo veio: política pública é a soma das

Souza atividades dos governos, que agem diretamente ou através de delegação, e que influenciam a (2007) vida dos cidadãos. Dye (1984) sintetiza a definição de política pública como 'o que o governo escolhe fazer ou não fazer'. A definição mais conhecida continua sendo a de Laswell, ou seja, decisões e análises sobre política pública implicam responder às seguintes questões: quem ganha o quê, por que e que diferença faz".

(...) políticas públicas (policy) são uma das resultantes da atividade política (politics): compreendem o conjunto das decisões e ações relativas à alocação imperativa de valores

Rua (2013) envolvendo bens públicos. "É importante desenvolver a compreensão de que as políticas públicas são resultantes da atividade política e que esta consiste na resolução pacífica de conflitos, processo essencial à preservação da vida em sociedade".

"são decisões que envolvem questões de ordem pública com abrangência ampla e que visam à satisfação do interesse de uma coletividade. Podem também ser compreendidas como Amabile estratégias de atuação pública, estruturadas por meio de um processo decisório composto de (2012) formal legalmente constituída para promovê-las, mas tal encargo vem sendo cada vez mais compartilhado com a sociedade civil por meio do desenvolvimento de variados mecanismos de participação no processo decisório".

"a policy-making trata fundamentalmente de atores cercados por restrições que tenham que

Howlett et compatibilizar objetivos políticos (policy goals) com meios políticos (policy means) em um al. (2013) processo que pode ser caracterizado como "resolução aplicada de problemas"no processo decisório".

"uma diretriz elaborada para enfrentar um problema público [...], uma política é uma orientação

Secchi

(2015) à atividade ou à passividade de alguém; as atividades ou passividades decorrentes dessa orientação também fazem parte da política pública". 
A partir das definições sobre 'política pública' alhures delineadas percebe-se que, até então, o governo atua como ator principal para consecução das finalidades de uma sociedade justa e igualitária e para tanto a política pública desempenha papel central na vida das pessoas, por ser um fator primordial para contribuir com o bem-estar da sociedade.

Portanto, parte-se do pressuposto que as políticas públicas são formuladas para propiciar melhores condições de bem-estar à população e, a sociedade, enquanto fim da política pública, possui papel substancial em seu processo de definição, elaboração, implementação e avaliação.

Nesse aspecto, o Brasil se destaca como país que se beneficiou, na última década, por adotar políticas de promoção do crescimento com equidade, mesmo que ainda necessite avançar para aprimorar o alcance dessas políticas (DEDECCA; TROVÃO; SOUZA, 2014), conforme a Figura 1 a seguir.

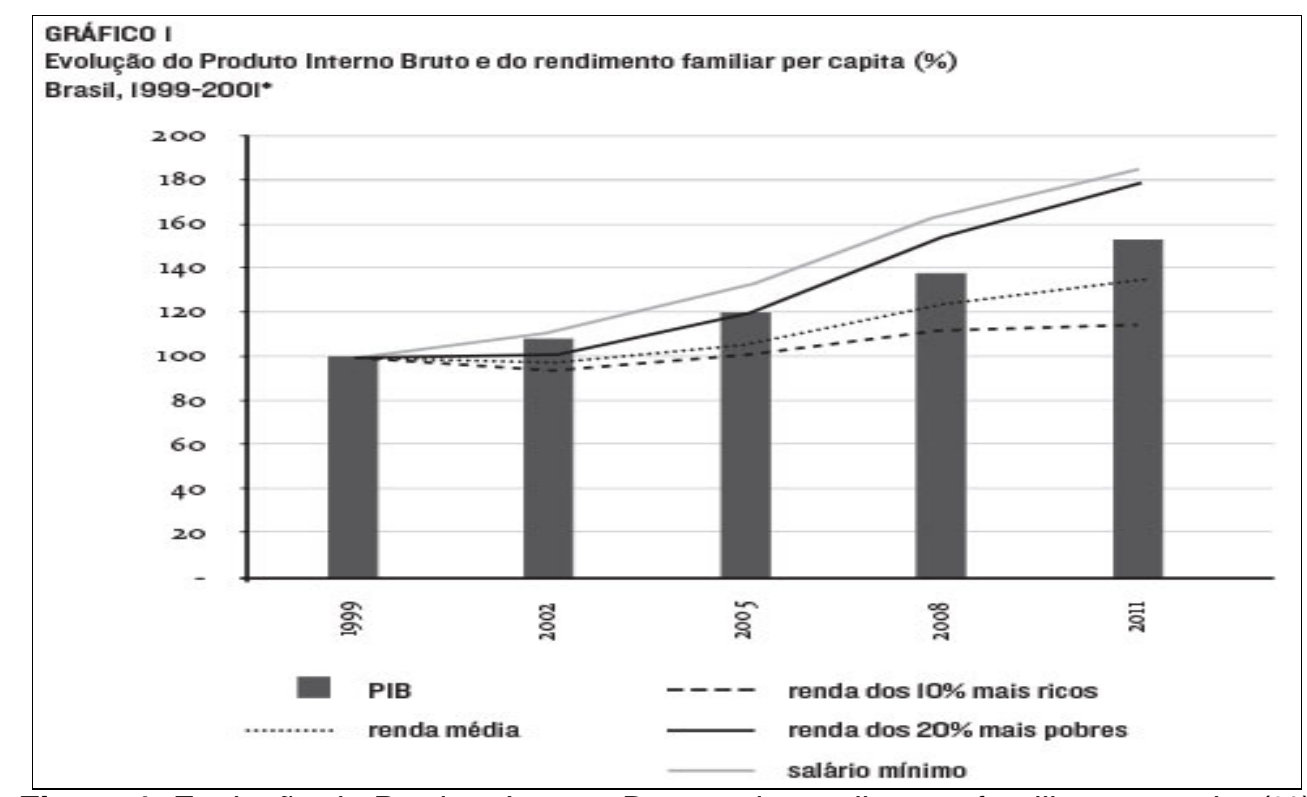

Figura 1. Evolução do Produto Interno Bruto e do rendimento familiar per capita (\%)

Fonte: IBGE, Diretoria de Pesquisas, Coordenação de Trabalho e Rendimento, Pesquisa Nacional por Amostra de Domicílios Contínua, 2014.

Assim, para que a sociedade supra suas necessidades, o governo precisa ser eficaz na produção das políticas públicas, realizando-as de forma satisfatória, pois as boas políticas públicas são construídas de forma consciente, ou seja, os governos necessitam de processos eficientes para alocar e equilibrar as demandas de forma a solucionar 0 núcleo dos problemas. 
Considerando essa complexa relação entre governo e sociedade, o processo político está repleto de irracionalidades, de inconsistências e de razões para a falta de coordenação. Essas deficiências derivam, muitas vezes, de fonte de políticas pouco resistentes, visto que, se tanto as pessoas que participam quanto as que não participam dos governos deixam de ter familiaridade com a natureza e o funcionamento do processo político, elas provavelmente não consigam imaginar estratégias de sucesso para influenciar seu rumo e assegurar que elas produzam resultados eficazes (HOWLETT; RAMESH; PERL, 2013).

Muito embora as políticas públicas sejam imprescindíveis à sociedade, elas ocupam um lugar central no mundo da gestão pública, posto que os gestores necessitam de recursos para executar suas tarefas em níveis elevados de inteligência, sofisticação e competência. Um processo político desarticulado influencia o funcionamento das políticas e neste ínterim os gestores não são capazes de elaborar estratégias eficazes para influenciar positivamente a direção do processo para garantir um conjunto integrado de resultados (WU et al., 2014).

Assim, a desarticulação do processo de políticas públicas, acarretou ao longo das décadas, problemas causados pela existência de uma gama de políticas fragmentadas, conforme será exposto na próxima seção.

Antes, cabe aqui destacar que, como visto, o conceito de política pública é transversal a diversas áreas ou setores de intervenção pública se ajustando de acordo com o problema público identificado, estabelecendo uma relação causal. Em outras palavras, dependendo do tipo de política pública que está em jogo, a estruturação dos conflitos, das coalizões e o equilíbrio de poder se modificam, determinando a dinâmica política e quiçá o processo político.

Portanto, para os fins desejados deste estudo, o conceito de Secchi (2015) é o mais indicado, pois entende que as políticas públicas devem ser desenvolvidas para 0 enfrentamento de um problema público com a finalidade de orientar as atividades para resolução do problema ou mesmo em casos de omissão ou passividade, as políticas públicas também são capazes de suprir tais carências.

\subsection{A Dinâmica do Ciclo das Políticas Públicas}

As políticas públicas (policies) ocorrem em um ambiente tenso e de alta densidade política (politics), marcado por relações de poder, extremamente problemáticas, entre atores do estado e da sociedade, entre agências intersetoriais, entre os poderes do 
estado, entre o nível nacional e níveis subnacionais, entre comunidade política e burocracia.

O processo de elaboração de políticas públicas (policy-making) também é conhecido como ciclo de políticas públicas (policy cycle). Tal ciclo é um esquema de visualização e interpretação, que organiza a vida de uma política pública em fases sequenciais e interdependentes.

Pode se dizer ainda que o ciclo é uma abordagem para o estudo das políticas públicas, que identifica fases sequenciais e interativas-iterativas no processo de produção de uma política, sendo que o modelo do "ciclo das políticas públicas" é uma concepção abstrata do processo político, que embora não corresponda exatamente ao que acontece na prática, funciona como um recurso de análise das políticas públicas. Por isso é denominado de "modelo heurístico" (RUA, 2014).

Saravia e Ferrarezi (2006) distinguem os seguintes estágios: formação da agenda, elaboração das alternativas, formulação, implementação, execução, acompanhamento e avaliação.

Contudo, Secchi (2010, p.44) entende que a "visualização do ciclo de políticas públicas se restringe a sete fases principais: 1) identificação do problema, 2) formação da agenda, 3) formulação de alternativas, 4) tomada de decisão, 5) implementação, 6) avaliação, 7) extinção", propondo o esquema mostrado na Figura 2, a seguir:

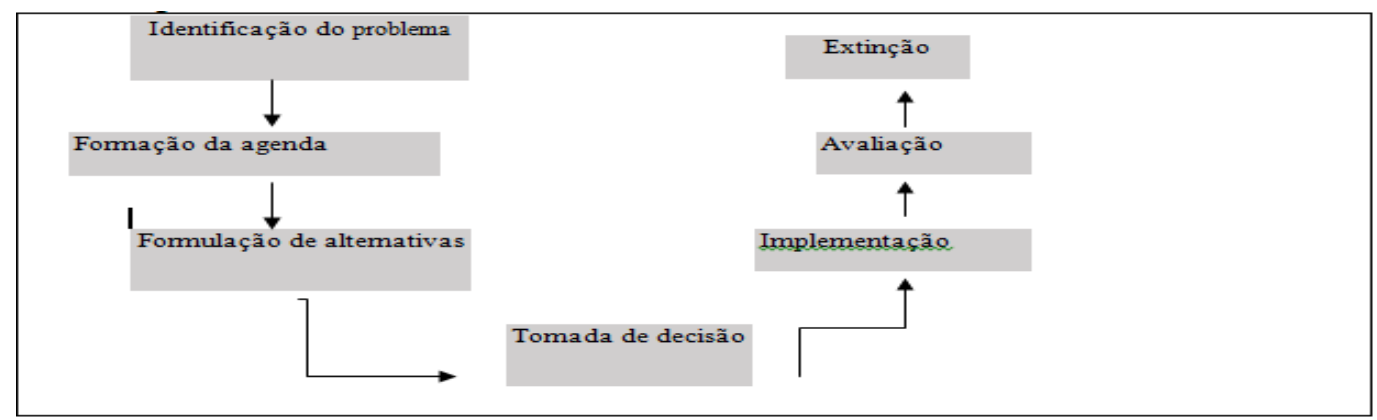

Figura 2. Ciclo de Políticas Públicas

Fonte: Adaptado de Secchi (2015, p.43).

Em linhas gerais, as fases principais de uma política pública, são conforme quadro 6 abaixo: 
DOI: 10.18605/2175-7275/cereus.v11n4p99-122

Revista Cereus

2019, vol. 11, ํo 4 .
Scotta, K.C.P.

Aspectos dinâmicos e qualitativos da política pública municipal de fomento ao cooperativismo.

Tabela 2. Principais fases de uma política pública

\begin{tabular}{|c|c|}
\hline ETAPAS & DESCRIÇÃO \\
\hline $\begin{array}{l}\text { Formação da } \\
\text { agenda }\end{array}$ & $\begin{array}{l}\text { reconhecimento e definição de determinada situação como problema político } \\
\text { coletivo relevante, podendo tomar forma de um programa de governo e/ou } \\
\text { de planejamento orçamentário; }\end{array}$ \\
\hline $\begin{array}{l}\text { Formação de } \\
\text { alternativas e } \\
\text { tomada de } \\
\text { decisão }\end{array}$ & $\begin{array}{l}\text { a partir definição do problema na agenda, os esforços de construção e } \\
\text { combinação de soluções para os problemas são imprescindíveis, } \\
\text { necessitando estabelecer os objetivos, estratégias e o estudo das potenciais } \\
\text { consequências de cada alternativa de solução. Trata-se do momento em que } \\
\text { são elaborados métodos, programas, estratégias ou ações que poderão } \\
\text { alcançar os objetivos estabelecidos. A tomada de decisão é vista como etapa } \\
\text { que sucede a formulação de alternativas de solução, onde os tomadores de } \\
\text { decisão têm problemas em mãos e correm atrás de soluções. }\end{array}$ \\
\hline $\begin{array}{l}\text { Implementação e } \\
\text { monitoramento }\end{array}$ & $\begin{array}{l}\text { esta fase sucede à tomada de decisão e antecede os primeiros esforços } \\
\text { avaliativos, onde se produz os resultados concretos da política pública, as } \\
\text { regras, rotinas e processos sociais são convertidos de intenções em ações, } \\
\text { analisando o desempenho frente aos objetivos traçados; }\end{array}$ \\
\hline Avaliação & $\begin{array}{l}\text { nesta fase do ciclo de políticas públicas o processo de implementação e } \\
\text { monitoramento são examinados com intuito de conhecer melhor o estado da } \\
\text { política e o nível de redução do problema que a gerou, ou seja, momento } \\
\text { crucial para a produção de feedback sobre as fases antecedentes. }\end{array}$ \\
\hline
\end{tabular}

Fonte: Adaptado de Secchi (2015).

Já para Rua (2013, p.36) "uma forma de lidar com essa complexidade, sem descartar a dinâmica sistêmica, é associar o modelo sistêmico com o modelo do ciclo de política (policy cycle), que aborda as políticas públicas mediante a sua divisão em etapas sequenciais", conforme visualização na Figura 3:

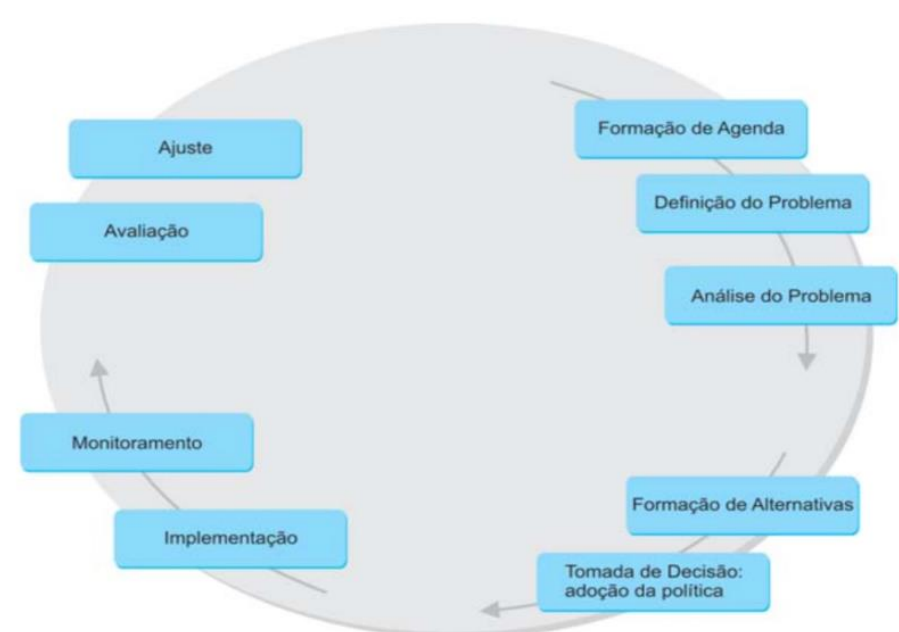

Figura 3. Ciclo de Políticas Públicas associado ao modelo sistêmico.

Fonte: RUA (2009, p.36).

Secchi (2010) diverge de Rua (2013) por considerar que as etapas são compreendidas não como um processo linear, sendo que o ponto de partida não está claramente definido e as atividades de etapas distintas podem ocorrer simultaneamente 
ou as próprias etapas podem apresentar-se parcialmente superpostas.

Entretanto, a forma correta de compreender o ciclo das políticas públicas é de suma importância para o gestor, pois o entendimento desse processo poderá contribuir para reflexões claras sobre como e quais instrumentos das políticas podem ser empregados e aperfeiçoados. Ademais, ajuda a organizar as ideias, faz que a complexidade de uma política pública seja simplificada e ajuda os atores a criar um referencial comparativo para casos heterogêneos (SECCHI, 2010).

Ao que este trabalho se propõe, no que tange aos objetivos traçados, em especial na dinâmica intermitente/cíclica da política pública de fomento ao cooperativismo existente, o desenvolvimento da pesquisa está relacionado com a gestão municipal e a plataforma de governo.

Notadamente em Gurupi-TO, no âmbito da estrutura administrativa da gestão pública municipal existe a secretaria de governo direcionada ao cooperativismo, apesar de estar vinculada com outras estruturas (Secretaria Municipal de Produção, Cooperativismo e Meio Ambiente).

Assim, considerando que a importância da concepção do "ciclo das políticas públicas" decorre do fato de que suas etapas correspondam a uma sequência de elementos do processo político-administrativo e podem ser investigadas no que diz respeito aos atores, às suas relações, seus recursos de poder, às redes políticas e sociais e às práticas ou ações que se encontram tipicamente em cada fase, passemos a abordar em como uma política pública existente pode ser mensurada e analisada, quais efeitos produzidos na sociedade ou grupo pela política pública, especialmente no que diz respeito às realizações obtidas e às consequências previstas e não previstas (SARAVIA; FERRAREZI, 2006).

Diante disso, os objetivos e ações implementadas na área do cooperativismo pela secretaria do governo local bem como as diretrizes nacionais e estaduais são imprescindíveis para a avaliação da política existente, com a finalidade de identificar os desafios que a norteiam e a sua avaliação qualitativa.

Portanto, para a compreensão do contexto de implementação da política pública municipal para o fomento do cooperativismo, passa-se a explanar sobre o cooperativismo local. 


\section{O COOPERATIVISMO NO ASPECTO LOCAL}

As cooperativas são veículos de mobilização de recursos nas comunidades onde estão localizadas haja vista o empenho na promoção de ações que fomentam a produção de bens e serviços e consequentemente beneficia a circulação de recursos na própria comunidade bem como propicia o desenvolvimento social e econômico.

E dentre os aspectos do desenvolvimento local, a atividade cooperativa também promove a geração de emprego e renda, pois através do sistema de cooperativa o cidadão tem condições de se inserir na compra, venda, uso e fornecimento de bens e serviços se beneficiando de melhores condições de trabalho e renda, gerando oportunidades e qualidade de vida no meio.

Segundo dados da SESCOOP sobre o panorama do cooperativismo no Estado do Tocantins o ano de 2015 fechou com um total de 45 cooperativas distribuídas nos ramos elencados na Tabela 3, a seguir:

\begin{tabular}{cc}
\multicolumn{2}{c}{ Tabela 3. Ramos de cooperativas no Tocantins } \\
\hline RAMOS DE COOPERATIVAS & ANO DE 2015 \\
\hline Agropecuário & 14 \\
\hline Consumo & 0 \\
\hline Crédito & 03 \\
\hline Educacional & 04 \\
\hline Especial & 0 \\
\hline Habitacional & 0 \\
\hline Infraestrutura & 0 \\
\hline Mineral & 03 \\
\hline Produção & 01 \\
\hline Saúde & 07 \\
\hline Trabalho & 06 \\
\hline Transporte & 07 \\
\hline Turismo e Lazer & 0 \\
\hline TOTAL & $\mathbf{4 5}$
\end{tabular}

No município de Gurupi-TO, a que este trabalho se dirige, o cooperativismo é idealizado como um pilar na gestão pública, a exemplo da edição da Lei Municipal n. ${ }^{\circ}$ 1.188 de 30 de junho de 1997, que trouxe a necessidade do fortalecimento do cooperativismo, como articulação de medidas de melhoria da população do meio rural. $A$ partir de então o cooperativismo é a base de sustentação para a implementação da política pública municipal desenvolvimentista.

No município as potencialidades locais podem ser avaliadas a fim de diagnosticar as condições para o desenvolvimento econômico, social e cultural da comunidade envolvida. Diante disto, o cooperativismo pode contribuir para a melhoria da qualidade de vida daqueles que estejam em condições econômicas e sociais vulneráveis. 
No caso de Gurupi-TO o potencial local está ligado às atividades agropecuárias, devido a potencialidade promissora da região e sua consolidação no mercado, como polo regional do sul tocantinense.

Segundo dados do sistema OCB/Sescoop em Gurupi existem 08 (oito) cooperativas ativas, conforme listadas na Tabela 4.

Tabela 4. Cooperativas ativas em Gurupi - TO.

\begin{tabular}{|c|c|}
\hline N. & COOPERATIVAS \\
\hline 1 & UNIMED GURUPI COOPERATIVA DE TRABALHO MÉDICO (Continua) \\
\hline 2 & COOPERATIVA DOS PRODUTORES DE CARNE E DERIVADOS DE GURUPI - COOPERFRIGU \\
\hline 3 & $\begin{array}{l}\text { COOPERATIVA DOS PRODUTORES AGROPECUÁRIOS DO SUL DO TOCANTINS - } \\
\text { COOPERSUL }\end{array}$ \\
\hline 4 & COOPERATIVA DE USUARIOS DE ASSISTENCIA MEDICA USIMED GURUPI \\
\hline 5 & IA REGIONAL DOS PRODUTORES DA AGRICULTURA FAMILIAR - C \\
\hline 6 & $\begin{array}{llllllll}\text { COOPERATIVA CENTRO } & \text { BRASILEIRA } & \text { DE } & \text { ECONOMIA } & \text { E } & \text { CRÉDITO } & \text { MÚTUO } & \text { DOS } \\
\text { PROFISSIONAIS DA SAÚDE LTDA } & & & & & & \end{array}$ \\
\hline 7 & $\begin{array}{l}\text { SICOOB CREDIPAR - COOPERATIVA DE CRÉDITO E LIVRE ADMISSÃO DE PARAÍSO DO } \\
\text { TOCANTINS E REGIÃO LTDA }\end{array}$ \\
\hline 8 & $\begin{array}{l}\text { SICREDI - COOPERATIVA DE CREDITO RURAL E DOS SERVIDORES PÚBLICOS E } \\
\text { DO ESTADO DO TOCANTINS }\end{array}$ \\
\hline
\end{tabular}

Fonte: OCB/Sescoop (2018, s/p).

Durante a realização deste trabalho foi percebido o grau de relevância da atuação destas cooperativas para o desenvolvimento local, considerando seu impacto social e econômico.

\section{MATERIAIS E METODOS}

Trata-se de uma pesquisa de abordagem qualitativa, por meio do método dedutivo, de caráter compreensivo, explicativo, pensando-se na avaliação com conotação política da política pública municipal de fomento ao cooperativismo no município de Gurupi-TO.

A pesquisa se dividiu em três etapas básicas: na primeira desenvolveram-se as pesquisas documental e bibliográfica; na segunda utilizou-se a técnica de coleta dados (neste estudo adotou-se a entrevista semiestruturada utilizando as técnicas bola de neve e saturação teórica); e na terceira e última etapa, consistiu na análise dos dados, utilizando como suporte a técnica de análise de conteúdo de Bardin (2016). Ambos evidenciaram as categorias de avaliação na construção do resultado da pesquisa.

Tendo definido o problema, os objetivos da pesquisa original e a metodologia a ser empregada, partiu, portanto para a coleta dos dados da pesquisa.

A coleta de dados documentais, consistiu em pesquisa bibliográfica e de documentação, ou seja, busca de leis e modelos de políticas públicas de enfrentamento existentes no país, em seus bancos de dados governamentais e institucionais. As buscas 
foram realizadas mediante os seguintes principais indexadores de pesquisa: Políticas Públicas; Ciclo das Políticas Públicas; Avaliação de Políticas Públicas; Cooperativismo. Portanto, as fontes de informações são oficiais e públicas sendo basicamente documentais imediatas (Legislação, Projetos, Artigos e Periódicos científicos).

A partir dos modelos de políticas públicas voltados ao cooperativismo, existentes no Brasil, se a política pública no município de Gurupi-TO se assemelhe e que, especificamente, seja voltada ao fomento do cooperativismo. Uma vez identificada a política pública municipal com este delineamento a mesma foi selecionada como objeto do estudo proposto, bem como os atores envolvidos na sua condução e os beneficiados pelas suas ações, os quais participaram após a necessária aprovação do projeto pelo Comitê de Ética em Pesquisa do Centro Universitário UnirG através do Parecer n.ํㅡ 2.617.639, mediante aceite e assinatura do TCLE, para a realização de entrevistas individuais semiestruturadas.

O quantitativo de amostra para realização das entrevistas individuais seguiu a técnica da saturação teórica de Fontanella et al., (2008, p.17) a qual implica no "fechamento amostral por saturação teórica é operacionalmente definido como a suspensão de inclusão de novos participantes quando os dados obtidos passam a apresentar, na avaliação do pesquisador, certa redundância ou repetição, não sendo considerado relevante persistir na coleta de dados".

A percepção do ponto de saturação teórica é "quando os dados obtidos passam a apresentar, na avaliação do pesquisador uma certa redundância ou repetição, não sendo considerado relevante persistir na coleta de dados" (FONTANELLA; RICAS; TURATO, 2008, p.17). Desta forma, havendo repetição e nenhuma inovação na reflexão teórica na entrevista é sinal de que se alcançou a saturação.

A exemplo, foi formulado o quadro que demonstra a saturação teórica quanto à categoria das ações desenvolvidas pela política municipal de fomento ao cooperativismo na agricultura familiar em Gurupi-TO, conforme Tabela 5 a seguir.

Tabela 5. Ações da política municipal de fomento ao cooperativismo na agricultura familiar

\begin{tabular}{|c|c|c|c|c|c|c|c|c|c|c|c|c|c|c|}
\hline \multirow{2}{*}{ Ações } & \multicolumn{13}{|c|}{ Entrevistas } & \multirow{2}{*}{$\begin{array}{l}\text { Total de } \\
\text { Recorrênci } \\
\text { as }\end{array}$} \\
\hline & $\underline{\text { 四 }}$ & 䍐 & 罵 & $\underset{\triangleright}{\mathbb{D}}$ & 嗯 & 四 & 罚 & 署 & 罟 & ○ 田 & $-\underline{\Phi}$ & $\sim \underline{\sim}$ & $\omega \underset{⿴}{\mathscr{\omega}}$ & \\
\hline $\begin{array}{l}\text { Preparação de } \\
\text { Solo } \\
\text { (maquinário) }\end{array}$ & $x$ & $x$ & & $\mathrm{X}$ & & $x$ & & $\mathrm{X}$ & $X$ & $\mathrm{X}$ & $X$ & $X$ & $X$ & 10 \\
\hline Insumos & & $\mathrm{X}$ & & & & & & & & & & & & 1 \\
\hline
\end{tabular}




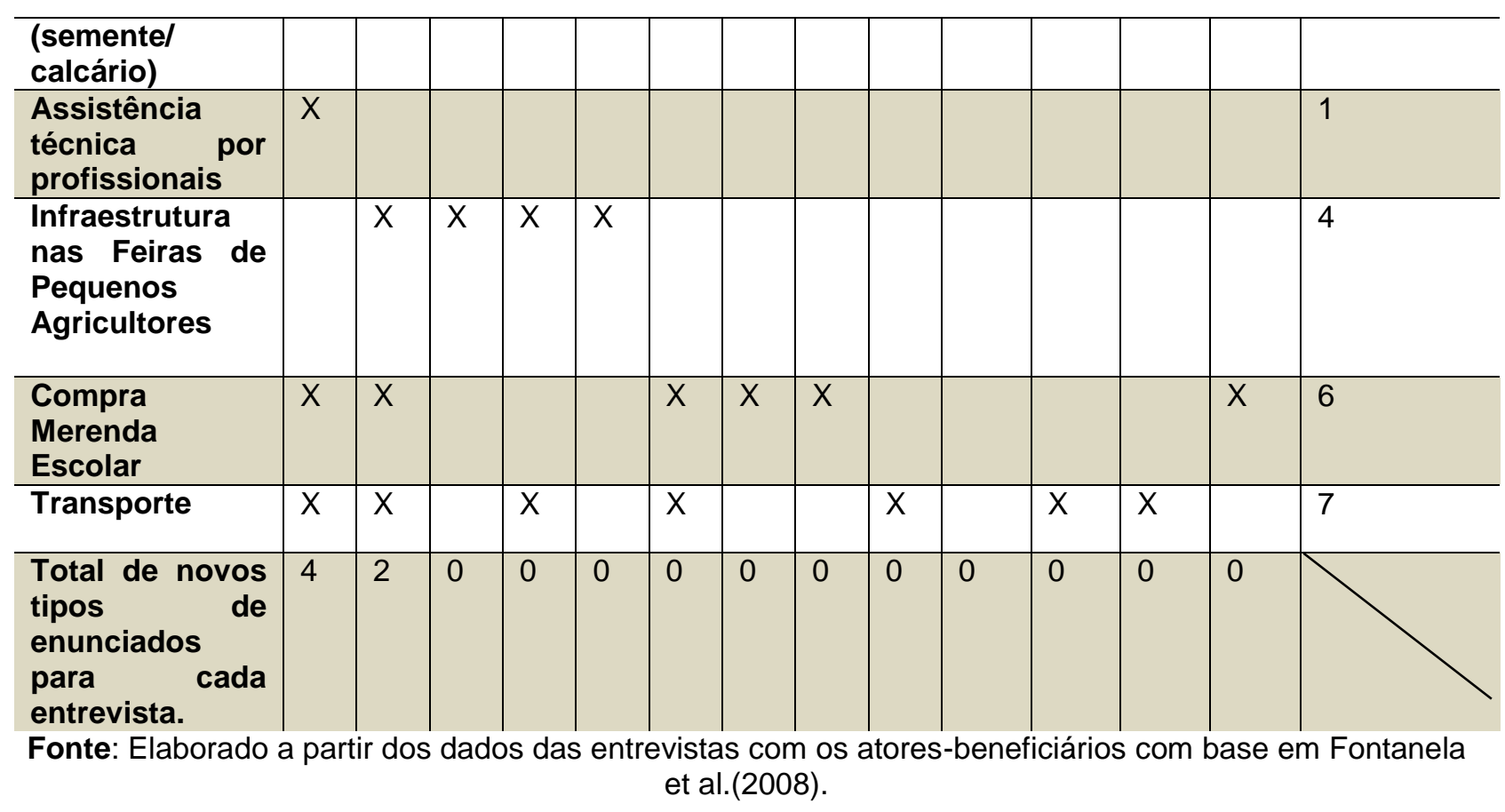

Pela Tabela 5 percebe-se a saturação teórica da categoria "Ações Desenvolvidas", visto que os novos enunciados surgiram apenas nas duas primeiras entrevistas e nas demais houveram repetições dos enunciados e nenhuma inovação a esta categoria da entrevista semiestruturada aplicada.

O esforço de coleta de dados também foi realizado através de entrevistas individuais semiestruturadas com os gestores municipais (secretários e dirigentes), para o que foi necessária autorização tanto do gestor municipal quanto do responsável à sua época pela Secretaria Municipal de Produção, Meio Ambiente e Cooperativismo do município de Gurupi-TO. Obtida as autorizações, foi o momento de entrar em contato por telefone ou pessoalmente (considerando a disponibilidade do participante) com os ex-gestores que dirigiram a política pública municipal entre os anos de 2013-2017, sendo explicados os objetivos da pesquisa, e aos que aceitaram participar, foi agendada uma data para coleta do TCLE e realização da entrevista semiestruturada, as quais foram realizadas com 03 (três) ex-gestores e 01 (um) diretor, com duração média de 35 minutos, sendo identificados por G1, G2, G3 e G4 para a preservação da confidencialidade das identidades e das informações. As entrevistas foram gravadas, e posteriormente, transcritas, para então serem analisadas.

A partir da coleta dos dados, estes foram analisados mediante o Análise de Conteúdo, com a formulação de categorias as quais explicitam as constatações dos objetivos específicos traçados e encontrados conjuntamente com a descrição da política pública avaliada e as conclusões finais da pesquisa mediante a interpretação que se 
exige nesta técnica metodológica.

Torna-se importante ressaltar que para fins desta pesquisa, se adotou a sequência de passos, para a realização da análise de conteúdo preconizada por Bardin (2016), tendo em vista sua ampla utilização e popularidade nas pesquisas qualitativas Para tanto foram definidas as categorias de análise conforme foram surgindo à pesquisadora, ou seja, a grade de análise foi do tipo aberta.

Os resultados foram obtidos da análise de conteúdo da pesquisa documental e bibliográfica e das entrevistas realizadas com os atores sociais no total de 17 atores, sendo 04 ex-gestores e 13 beneficiários associados às organizações associativistas/cooperativistas no município de Gurupi-TO.

Agora, são apresentados os resultados do trabalho.

\section{RESULTADOS E DISCUSSÃO}

A partir da metodologia empregada, passou-se a analisar e avaliar qualitativamente a dinâmica institucional do ciclo da política pública municipal de fomento ao cooperativismo entre os anos de 2013 a 2017 com o propósito de identificar os desafios e propor diretrizes para a consolidação da gestão municipal da política publica de fomento ao cooperativismo existente em Gurupi-TO.

A avaliação é a fase do ciclo de políticas públicas em que o processo de implantação e o desempenho da política pública são examinados com o intuito de conhecer melhor o estado da política e o nível de redução do problema que a gerou.

O presente trabalho privilegiou uma avaliação com conotação política, segundo (SECCHI, 2015), considerando os aspectos como: a legitimidade do processo de elaboração das ações, a percepção dos beneficiários da política pública com a indicação dos benefícios e impactos e a participação dos atores na condução da política pública de fomento ao cooperativismo.

No que se refere à legitimidade do processo de elaboração das ações, G3 e G4 apontaram a existência e relevância do Conselho de Desenvolvimento Rural Sustentável no qual são debatidos os problemas existentes enfrentados tanto pela gestão quanto pelos produtores/beneficiários da política existente sendo confirmado pelo beneficiário B2, note

(...) o Conselho de Desenvolvimento Rural Sustentável que foi criado também já nesta gestão justamente a gente por exemplo analisa as ações desenvolvidas e as que não deu muito certo nesse ano o que que a gente pode estar fazendo para melhorar (...); Ouvindo eles, as Associações são 
representadas no Conselho e tem participado das reuniões, a gente faz um planejamento com a participação deles, não é um planejamento que sai apenas da Diretoria (G4).

Tem as entidades relevantes que participam das ações desenvolvidas como o Conselho de Desenvolvimento Rural (G3).

(...) a gente tem um Conselho de Desenvolvimento Rural Sustentável que eu acho que é o que cuida mais dessas ações, determina (B2).

Os depoimentos demonstram a existência de um canal legítimo e organizado de forma paritária para as deliberações relativas á política pública existente, permitindo a influência dos cidadãos nas decisões tomadas.

Sobre a percepção dos benefícios e impactos gerados pela política pública existente de fomento ao cooperativismo, os benefícios mencionados são: melhoria do trabalho e da renda por meio de programas governamentais de compra de produtos, a melhoria na produtividade por meio das assistências técnicas e apoio com infraestrutura com a melhoria das estradas, oferta de transporte de produtos para venda e dos insumos.

Tais benefícios e impactos são assim relatados pelos beneficiários

A gente tinha bastante incentivo da prefeitura tanto na apicultura quanto na agricultura (...); a prefeitura deu cursos de apicultura, deu um pouco de material, deu as caixas, macacão, foi 4 caixas para cada produtor, foi aí que começou a produção de mel na região de Gurupi (...); Olha eles [a gestão] sempre dão assistência técnica pra gente, o técnico vai lá pra ajudar no plantio, no preparo da terra (B1).

Tem o programa de desenvolvimento rural através da agricultura familiar para dar assistência pra nós no caso do preparo do solo. Nós temos a condução [transporte] pra pegar nossos produtos aqui porque a gente vende pra prefeitura pra merenda escolar (B2).

Temos de benefício a feira do produtor que é muito boa pra vender (B3).

Os benefícios que nós temos é que com a feira aumentou a renda do produtor, melhorou bastante (B4).

Nós temos cursos para melhorar a produção e esta feira que é boa demais (B5).

Ela [a gestão] arruma as estradas quando precisa, manda as máquinas pra gradear, jogar calcário, isso é muito bom pra nós (B6).

As feiras veio na hora certa pra gente conseguir vender os produtos la da roça (B7).

Aumenta a renda porque a gente passou a vender mais nas feiras e pra merenda escolar (B8).

Eles levam tratores pra ajudar no preparo da terra e nas estradas, manda carro pra nós despachar as mercadorias pras escolas e nas feiras (B9).

Ela [gestão] dá os tratores para gradear as terras, dá muito apoio e benefício pra nós (B10).

Eles [gestão] dão o trator, o ônibus pra buscar e levar nós, faz ponte e arruma as estradas (B11).

Temos trator e ônibus para ajudar nós (B12).

A compra direta melhorou muito nossa renda, os tratores na época do plantio é muito bom pra ajudar na plantação (B13). 
Os ex-gestores também relatam sobre os benefícios da política existente

(...) hoje o resultado que nós temos ai é uma feira organizada que acontece 3 vezes por semana (G1).

(...) as políticas públicas, por exemplo, do compra direta, com doação simultânea, das compras governamentais pela própria secretaria de educação aonde pelo menos $30 \%$ da merenda escolar ela tem que vim da origem agricultura familiar então essas políticas públicas elas existem aqui (...) (G2).

(...) a patrulha mecanizada foi uma importante aquisição para fomentar a produção local, a gestão oferta o operador da maquina, o combustível tudo para facilitar a vida do pequeno produtor (G3).

(...)os produtores hoje eles recebem apoio desde o preparo do solo, orientações, cursos, de apicultura, agricultura orgânica e vários outros custos até mesmo de NCR (negócio certo rural), aprender como se planeja sua produção, até a hora de comercializar, eles tem um apoio logístico, foram criadas três feiras exclusivas para eles [beneficiário] (G4).

Os depoimentos acima evidenciam que a política existente gera benefícios e por consequência impacta positivamente a vida destes beneficiários, ou melhor, proporciona melhor qualidade de vida. Por isso, é perceptível o avanço em relação aos efeitos da política pública analisada como alternativa na resolução do problema social relacionado à oferta de trabalho e renda desta parcela da população, qual seja, da agricultura familiar.

Quanto à participação dos atores na condução da política a maioria manifestou exercer com liberdade sua participação, falando, ouvindo, dando sugestões nas deliberações coletivas, a seguir os depoimentos

Muitas vezes eles [gestores] já levam o projeto pronto, apresenta e orienta a gente participar porque é bom pra nós. Muitas vezes marcam reunião, a associação convida o pessoal e muitas vezes eles [beneficiários] não vão (...); A gestão sempre que tem alguma coisa a fazer eles convidam e participam e a maioria dos produtores só ouve (B1).

Sempre que está em reunião com a gente, sempre participo (...) (B2).

Eu sempre falo e às vezes me ignoram porque não venho nas reuniões pra ficar calado, porque se eu não falar não vão saber o que estamos sentindo ou precisando (B3).

De vez em quando tem reunião sim, a gente participa (...) (B4).

Já participei de algumas reuniões, mas não sou de falar muito, só de ouvir (B5).

Sempre que tem reunião é muito boa e proveitosa (B6).

A prefeitura faz reuniões frequentes, teve uma mês passado e eu tenho participado (B7).

Eles sempre fazem reuniões com a gente, tem umas que fui e outras não (B8).

Para este critério, de acordo com Tenório (2010, p.6) é definida como: "dotados de informação e com acesso livre aos canais de deliberação, qualquer individuo (cidadão) ou organização é passível de influenciar as decisões tomadas via processo deliberativo". 
Portanto, as falas acima mostram a importância da participação das pessoas na busca de seus direitos, quanto mais a pessoa participa, mais ela busca conhecimento dos seus direitos e deveres, mas sem atuar, fica difícil de melhorar a qualidade de vida em todos os setores, seja no trabalho, na educação ou saúde.

Nas entrevistas semiestruturadas realizadas com ambos os atores, foi-lhes perguntado: "Em uma escala de 1 a 5, sendo: 1- ruim; 2- regular; 3-bom; 4- muito bom e 5-excelente, qual seria sua avaliação da política existente.

O resultado da avaliação conclui que o público entrevistado dividiu-se no resultado final, sendo que $52,93 \%$ considerou satisfatória (bom a excelente) a política de fomento ao cooperativismo de Gurupi-TO e $41,18 \%$ a considerou regular (ruim a regular), ressalvando aspectos da política a serem aperfeiçoados.

Acho que deveria melhorar a comunicação entre os gestores e os produtores, porque muitas reuniões são marcadas e o pessoal da prefeitura não vai (B1).

Tem que ter um melhor empenho na implantação do CEASA para nós, seria um incentivo pra produzir e vender mais (B3).

A gestão poderia acompanhar as associações mais de perto e ver como elas funcionam e precisam de ajuda para melhorar (B5).

Melhorar as estradas (B6/B7/B8/B12 e B13).

Na percepção dos ex-gestores

A política precisa ter continuidade, se a cada gestão você tem uma interrupção você tem uma volta ao passado, então a motivação, tudo que você faz tem que ter uma sequência, persistência, tem que perseverar porque se você sofrer interrupção você tem retrocesso (G1).

(...) a cultura da cooperação ela tem que ser excelente pra Gurupi e região, agora hoje ela não se faz excelente então nós temos uma oportunidade de preconizar uma cultura diferente e ai eu acredito a própria secretaria, o trabalho realizado vai oportunizar isso a caminhos pra gente se torna excelente que hoje eu vejo como insipiente que as pessoas não falam, é acanhado, as pessoas na verdade quando fala de cultura de cooperativismo as pessoas, elas maculam aquela imagem antiga da cooperativa que não deu certo na nossa região, nós precisamos sim, de ter uma política pública que instrumentaliza, agora esse é um grande desafio porque nem todo mundo quer o sistema produtivo organizado e estruturado (G2)

(...) os gestores não tem afinidade em trabalhar com a parte do cooperativismo. Aqui não tem diretor de cooperativismo. Então como fomentar isso se você não tem pessoas em condição de trabalhar. É assim se colocar as pessoas no lugar certo elas vão desenvolver as coisas certas. Então você vai colocar pessoas erradas elas não vão desenvolver. Os secretários aqui são políticos, que é a coisa mais ridícula que eu já vi, esse deveria ser um cargo técnico (G3).

Temos muito que ainda melhorar nessa questão do cooperativismo e fazer com que a população e as classes produtivas possam entender a importância do cooperativismo para o desenvolvimento social e econômico da região. A nossa vantagem no momento é que a gente tem um gestor 
com essa visão voltada para incentivar o cooperativismo (G4).

Dentre os aspectos mencionados pelos entrevistados para o aprimoramento da política pública existente temos: a comunicação entre a gestão e os beneficiários, infraestrutura, monitoramento das associações beneficiadas, continuidade das ações na sucessão entre as gestões, educação e cultura para o aperfeiçoamento do cooperativismo local e nomeação de gestores e servidores técnicos e capacitados para desenvolver o cooperativismo local.

Tabela 6. Síntese da Avaliação da Política Pública na visão dos atores CRITÉRIOS

Legitimidade do processo de elaboração das ações

Percepção dos benefícios e impactos gerados

\section{DESCRIÇÃO}

O funcionamento do Conselho Municipal de Desenvolvimento Rural, sua formação paritária com a sociedade repercute na legitimação do processo deliberativo da política pública existente.

Foram mencionados pelos entrevistados alguns benefícios dentre os quais destacam-se: investimento na infraestrutura das estradas, assistência técnica para os produtores, patrulha mecanizada para preparo do solo, oferta de transporte público gratuito dos produtores e produção; compra direta e para merenda escolar da produção, gerando impacto na melhoria do trabalho e aumento na renda dos produtores.

\section{Participação dos atores na} condução da política
Manifestaram exercer com liberdade sua participação, falando, ouvindo, dando sugestões nas deliberações coletivas, com a possibilidade de acatamento pela gestão.

Fonte: Dados da pesquisa, 2018.

A política existente é direcionada ao desenvolvimento da produção local proveniente da agricultura familiar o público beneficiário está concentrado na formação das associações locais que possuem representatividade perante o Conselho Municipal de Desenvolvimento Rural bem como promove a intermediação das ações da gestão pública municipal para os associados proporcionando impactos positivos na geração de trabalho e aumento da renda familiar.

Portanto, a política pública municipal para o cooperativismo em Gurupi-TO baseando-se na percepção dos gestores públicos, dirigentes e beneficiários pode ser avaliada como parcialmente satisfatória visto que sua idealização e condução pauta-se na legitimidade das ações desenvolvidas as quais são decididas mediante deliberação coletiva em Conselho formado para tal finalidade, sendo este esfera constituída de forma paritária entre atores públicos, beneficiários e sociedade civil organizada e a participação dos beneficiários.

Sobre a condução da política pública foi mencionado pelos beneficiários que a participação se efetivou de forma livre e sem coações, apesar da ressalva de que nem todas as manifestações e solicitações não são acatadas pela gestão municipal, visto que 
cabe a esta decidir, pautada na discricionariedade, quais ações são realmente necessárias ao menor custo.

Quanto aos benefícios e os impactos promovidos pela política analisada, consistem na maioria das opiniões dos beneficiários, em ações de infraestrutura que viabilizam a produção local provenientes da agricultura familiar gerando impactos positivos e relevantes nas condições de trabalho e renda e por consequência na melhoria da qualidade de vida dos beneficiários, conforme demonstra a literatura recorrente.

Tem-se como desafios a serem enfrentados pela gestão da política pública: a consolidação da efetividade da política pública de fomento ao cooperativismo por meio de ações contínuas de educação e cultura cooperativista, manutenção de uma gestão pública dirigida por atores capacitados e comprometimento governamental e institucional para a consolidação de cooperativas rurais, em especial que abrange atividades de agricultura familiar.

Quanto ao aprimoramento dos canais de comunicação entre a gestão e os beneficiários, a divulgação das ações e deliberações bem como a participação efetiva dos beneficiários na gestão da política pública são temas de deliberação coletiva e que nas sessões ambos os atores podem manifestar e em consenso coletivo analisar o que melhor atende as necessidades.

Portanto, entende-se que a consolidação da gestão da política pública de fomento ao cooperativismo através dos indicadores ora analisados pode vir a ser efetivada através da edição de lei municipal que regulamente o cooperativismo e as ações desenvolvidas pela gestão municipal como instrumento estratégico na promoção do fortalecimento econômico, social e político dos beneficiários da política municipal de fomento ao cooperativismo.

\section{CONSIDERACOES FINAIS}

O objetivo central deste trabalho é analisar a dinâmica institucional da política pública municipal de fomento ao cooperativismo, entre os anos de 2013 e 2017, no município de Gurupi-TO, especificamente avaliar qualitativamente a dinâmica institucional da política pública municipal para o cooperativismo com base na percepção dos gestores públicos, dirigentes e beneficiários em relação ao desempenho qualitativo da política pública municipal e iidentificar os desafios e propor diretrizes para a consolidação da gestão da política pública de fomento ao cooperativismo no município de Gurupi-TO.

Com a interpretação e inferência a partir das entrevistas semiestruturadas foi 
possível avaliar o desempenho qualitativo da política pública municipal através de indicadores de conotação política (SECCHI, 2015) indicando que a política existente de fomento ao cooperativismo é satisfatória, contudo necessita aperfeiçoar os canais de comunicação entre a gestão e os beneficiários, infraestrutura e monitoramento das associações/cooperativas beneficiadas o que pode acontecer por meio da consolidação de um instrumento legal que possa garantir a continuidade das ações na sucessão das gestões municipais, efetivar a educação e cultura para o aperfeiçoamento do cooperativismo local e possibilitar a nomeação de gestores e servidores técnicos capacitados para desenvolver o cooperativismo local.

Quanto aos desafios e possíveis diretrizes para consolidação da gestão de política pública de fomento ao cooperativismo no município de Gurupi-TO, constata-se como desafios: a efetividade da política pública de fomento ao cooperativismo por meio de ações contínuas de educação e cultura cooperativista, manutenção de uma gestão pública dirigida por atores capacitados e comprometimento governamental e institucional para a consolidação de cooperativas rurais, em especial que abrange atividades de agricultura familiar.

No que tange ao objetivo que foi delineado este foi alcançado oferecendo subsídios para a resolução da problemática inicial (De que maneira a dinâmica institucional da política pública municipal de cooperativismo contribui para a consolidação do cooperativismo no município de Gurupi-TO? Quais os desafios e possibilidades da gestão de políticas públicas e do cooperativismo em âmbito local?)

Importante ressaltar que a política pública para o fomento do cooperativismo em Gurupi-To promove ações importantes para proporcionar a melhoria da qualidade de vida no meio rural especialmente aos pequenos produtores que desenvolvem suas atividades agrícolas em âmbito coletivo (assentamentos) e familiar, e enquanto membros de associações locais declararam na maioria das falas que conhecem o cooperativismo. Porém, a forma de organização e realização da produção são exercidos de forma manual com auxílio da gestão pública no incremento da produção e o trabalho intelectual é orientado pela organização a qual pertencem, caracterizando-se a autogestão e equiparando-se às cooperativas populares (CANÇADO, 2005).

No decorrer da pesquisa foi possível classificar as organizações dos beneficiários da política pública de fomento ao cooperativismo como classes populares menos favorecidas em situação de desemprego e exclusão social o que os agrega ainda mais à classe das cooperativas populares. 
As ações públicas, desenvolvidas em prol dos beneficiários com o fornecimento de meios de produção, também constituem outro elemento que se faz presente nas organizações dos agricultores familiares.

A política pública analisada resgata o papel do Estado, no caso o município de Gurupi-TO, como indutor do processo econômico, impulsionador das respostas econômicas e sociais às reivindicações dos beneficiários, qual sejam, os agricultores familiares.

A gestão da política pública analisada enfatiza a criação direta de oportunidade de trabalho aos trabalhadores organizados propiciando a emancipação social garantindo cidadania e inclusão social.

Com estas considerações tecidas foi possível destacar elementos que podem contribuir para a consolidação da política pública de fomento ao cooperativismo em Gurupi-TO através da elaboração de diretrizes, objetivos e instrumentos capazes de desenvolver estratégias de gestão na condução da política pública existente com propósitos de implantação de recursos humanos capacitados que visam a melhoria da população rural que vivem da agricultura familiar.

Assim pode-se afirmar que apesar dos desafios elencados, o fomento ao cooperativismo promove relevante influência e possibilidade no processo de inclusão social não só na busca de crescimento econômico, mas também como fortalecimento social e político dos beneficiários da política municipal de fomento ao cooperativismo.

\section{REFERËNCIAS}

AMABILE, A. E. N. Políticas Públicas. In: CASTRO, C. L. F.; GONTIJO, C. R. B.; AMABILE, A. E. N. (Org.). Dicionário de políticas públicas. Barbacena: EdUEMG, 2012. BARDIN, L. Análise de conteúdo. Lisboa: Edições 70, 2016.

BARROS, E. F. Estratégias Metodológicas para Avaliação de Programas Governamentais. In Anais do XI Congresso Brasileiro de Custos - Porto Seguro, BA, Brasil, 27 a 30 de outubro de 2004.

BOULLOSA, R. de F.; SCHOMMER, P. C. Gestão social: caso de inovação em políticas públicas ou mais um enigma de lampedusa. Encontro Nacional de Pesquisadores em Gestão Social, 2009. 
BRASIL. Constituição da República Federativa do Brasil, de 05 de outubro de 1988. Disponível em <http://www.planalto.gov.br/ccivil_03/Constituicao/Constituicao.htm> Acesso em 28 Nov. 2017.

BRAÚNA, A. A. O papel do cooperativismo no desenvolvimento do estado do Tocantins. 2016.

CANÇADO, A. C. Para a apreensão de um conceito de cooperativa popular. Encontro anual da ANPAD, v. 29, 2005.

CANÇADO, A. C. Gestão Social e Políticas Públicas de Desenvolvimento: Ações, Articulações e Agenda. 2010.

DEDECCA, Claudio Salvadori; TROVÃO, Cassiano José Bezerra Marques; SOUZA, Leonardo Flauzino de. Desenvolvimento e equidade: Desafios do crescimento brasileiro. Novos estudos CEBRAP, 2014, 98: 23-41.

DIAS, R. Políticas públicas: princípios, propósitos e processos. São Paulo: Atlas, 2012. DYE, T. R. Understanding Public Policy. Prentice-Hall, Englewood Cliffs, 1972.

ESTATUTO, DA TERRA. Lei no 4.504 de 30 de novembro de 1964. 2014.

FONTANELLA, Bruno José Barcellos; RICAS, Janete; TURATO, Egberto Ribeiro. Amostragem por saturação em pesquisas qualitativas em saúde: contribuições teóricas. Cadernos de saúde pública, 2008, 24: 17-27.

FREY, K. Políticas públicas: um debate conceitual e reflexões referentes à prática da análise de políticas públicas no Brasil. In Planejamento e políticas públicas, 2009.

HOWLETT, M.; RAMESH, M.; PERL, A. Política pública: seus ciclos e subsistemas-uma abordagem integral. São Paulo: Campus, 2013.

IBGE, IBGE. Instituto Brasileiro de Geografia e Estatística. Acesso em, 2018, 1.

INSTITUTO BRASILEIRO DE GEOGRAFIA E ESTATÍSTICA - IBGE. Brasil/Tocantins/Gurupi. Disponível em: <https://cidades.ibge.gov.br/brasil/to/gurupi/panorama>. Acesso: 16 Jan. 2018.

JENKINS, William leuan. Policy analysis: A political and organisational perspective. London: M. Robertson, 1978.

LEOPOLDINO, C. J.; DE QUADROS, L. C.. O direito cooperativo e sua normativa jurídica. Revista Faz Ciência, v.13, n.17, p.185, 2011.

MILAGRES, C. S. F.; AMODEO, N. B. P.; SOUZA, D. N. Cooperativas e desenvolvimento de comunidades: promessas e decepções. Viçosa: Revista de C. Humanas, Ano XI, no 1, 2011.

ORGANIZAÇÃO DAS COOPERATIVAS BRASILEIRAS - OCB. O cooperativismo brasileiro: uma história. Brasília, DF: Versão Br Comunicação e Marketing, 2004. Disponível em: < http://www.ocb.org.br/historia-do-cooperativismo. Acesso em 10 Jan. 2018. 
PEREIRA, J. R. Gestão social de políticas públicas. Lavras: Ed. UFLA, 2011.

RUA, M. G.; ROMANINI, R. Para aprender políticas públicas: conceitos e teorias. Curso online políticas públicas, 2013.

SECCHI, L. Políticas públicas: conceitos, esquemas de análise, casos práticos. São Paulo: Cengage Learning, 2010.

SECCHI, L. Análise de políticas públicas: diagnóstico de problemas, recomendação de soluções. São Paulo: Cengage Learning, 2015.

SILVA, R. D. L.; PETARLY, R. R. Responsabilidade Social Empresarial no Cooperativismo: O Dia de Cooperar como Estratégia de Voluntariado Cooperativista. Coleção Tocantins Cooperativo. Palmas, Vol. II, p. 141-155, 2015.

SOUZA, C. Estado da arte da pesquisa em políticas públicas. In Políticas públicas no Brasil. Rio de Janeiro: Fiocruz, 2007, p.65-86.

SOUZA, C. Políticas públicas: uma revisão da literatura. Sociologias [online]. 2006, n.16, p.20-45.

TENÓRIO, F. G. Gestão social, um conceito não-idêntico? Ou a insuficiência inevitável do pensamento. In RIGO, A. S.; SILVA JÚNIOR, J. T.; SCHOMMER, P. C.;

THISSEN, W.A.H.; WALKER, W. E. Public Policy Analysis. Springer, 2013.

TOCANTINS, SECRETARIA DA AGRICULTURA E PECUÁRIA DO ESTADO DO TOCANTINS - SEAGRO-TO. Diretoria de fomento e fortalecimento ao cooperativismo e do associativismo rural. Palmas - TO: Seagro, 2013. 